rhage, there being, of course, no help from uterine contraction, as in ordinary post partum hæmorrhage. Before her death, the idea was discussed, although hardly entertained, of reopening the abdomen, with the hope of discovering the source of the hæmorrhage; but we deemed it impracticable, and the results of the post mortem examination confirmed, I think, the correctness of the decision. I followed the plan, suggested, I believe, by Dr. Hicks, of stitching the edges of the cyst to the edges of the abdominal incision; but, although at the examination the stitches were found still holding, the cyst itself was so thin and soft, that it had given way in numerous places, and practically very little had been gained. For the first forty hours after the operation, the drainage-tube certainly did good service in permitting the ready withdrawal of effused fluid; but, for the last twelve, the fluid welled up around the tube and funis, and the tube was of little use. But, had she not sunk under the hæmorrhage, I cannot but think that, in the later stages of the case, the tube would have been of considerable service. As regards the bearing of the case on the subject generally, one would speak, as of the inferences to be drawn from any single case, with much diffidence. In the operation itself, no unforeseen difficulty was met with, and the risk to the patient was less than in the majority of cases of ovariotomy. The amount of disturbance of the peritoneum was slight, and the evidences found of peritonitis were also slight. But it would seem to sustain the view that the prognosis in these cases hinges very much on the position and behaviour of the placenta, and mainly, I think, from the point of view of its relation to the occurrence of hæmorrhage. If its disintegration and separation do not occur until the danger of hæmorrhage is averted by the establishment of thrombosis in the maternal vessels of the placental site, the dangers from subsequent peritonitis or septic infection would not appear to be great. In Mr. Jessop's case, for instance, many ounces of putrid fluid were on several occasions retained for a while and then discharged, and yet general septicæmia, at all events, did not occur. This probably has relation to the fact that septic fluids are not formed until granulation is in progress on those incised surfaces through which absorption is likely to occur. And, in Dr. Heywood Smith's case, death, I believe, took place from hæmorrhage within a few hours of the operation. The question, therefore, of supreme interest is this. It being by general consent admitted that it is unadvisable to interfere with the placenta at the time of operation, can any treatment of the placenta be suggested, by the local application of styptics or the use of ligatures, likely to lessen the chance of hæmorrhage by premature separation or disintegration of its tissues?

\section{ON THE TREATMENT OF AURAL EXOSTOSES.}

By LENNOX BROWNE, F.R.C.S.Edin.,

Senior Surgeon to the Central Throat and Ear Hospital; Surgeon and Aural Surgeon to the Royal Society of Musicians.

I HAVE nothing to say except in agreement with the etiology and pathology of aural exostoses as explained in the commendably concise and very interesting communication of Dr. Cassells; but I think an account of the treatment pursued in the following case may be interesting to readers of the JOURNAL.

Mr. J. S., aged 35, residing at Tunbridge, consulted me on April 16 th, 1877, on account of total deafness of the right ear, which had existed over four years. His history was that, eight years previously, feeling the ear itch, he had rubbed it with the finger and induced bleeding. He felt quite deaf for an hour, recovered his hearing partially, but had heard nothing for four years. Meantime, there had been a gradually increasing swelling, which had become denser as it grew ; occasionally, a little discharge oozed from behind the growth. He suffered intensely from facial neuralgia of the same side.

On testing his hearing, it was plain that his deafness was due simply to obstruction of the external meatus, which was quite filled by a smooth, 5 spherical, bony tumour covered with skin. With a curved probe, it was discovered to be attached by a narrow bony pedicle to the posterior wall, and attempts were made with every kind of forceps to wrench it off, but without success, as no hold could be obtained on the growth. I, therefore, took him round to Mr. Wallis in Queen Anne Street, and, having removed the dermal covering, I requested that gentleman to drill a hole in the tumour with the American treaddrill now in general dental use. (The moment the growth was perforated, the patient heard the watch at some inches.) I then, with a pair of fine tooth-forceps, one blade being placed in the perforation, easily evulsed the tumour, which, divested of skin, measured just two inches in circumference. There was but little pain or hæmorrhage, and the patient immediately regained perfect hearing. The surface was dressed with weak solution of chloride of zinc, and healed over in a few days. Dr. Matthewson, of Brooklyn, New York, reports a case somewhat similarly treated in the Edinburgh Medical fournal for November.

Finally, as an evidence of the advance which aural surgery has made, even in small matters, in the last few years, it may be stated that Toynbee (Diseases of the Ear, with a Supplement by James Hinton, page I IO) considered "that there are many weighty objections to any attempt to remove these tumours by operation or by escharotics", and advised "the use of iodine (externally and internally) and other absorbent medicines". My patient had also seen the late Mr. Harvey five years previously to his visit to me, and had been recommended to leave the growth alone.

\section{CASE OF RIGHT HEMIPLEGIA, OCCURRING DUR- ING THE SEVENTH MONTH OF PREGNANCY : RECOVERY ALMOST COMPLETE, AFTER PARTURITION.}

By W. R. THOMAS, M.D., M.R.C.P.,

Physician to the Sheffield Public Hospital and Dispensary; Joint Lecturer on Medicine at the Sheffield Medical School.

MRs. A., a married woman, aged 32, who had hitherto enjoyed good health, about the beginning of the seventh month of pregnancy, one morning, when attempting to rise out of bed, complained of a sensation of great weight in her head and dizziness, and immediately afterwards fell backwards, perfectly insensible and helpless, and breathed heavily. She remained in this state, I was told, for nearly half an hour, and then became conscious. On the previous day, she had suffered from slight dizziness, but otherwise felt well. She had had two children, and had soon recovered after her confinements. When I visited her, in about an hour after the attack, I found her sensible, but unable to speak; the right arm and leg were perfectly paralysed; when raised, they dropped like logs of wood; there was but very little sensation left in either limb; the right buccinator was flabby; and the tongue, when protruded, was turned towards the right. The muscles of the chest and abdomen' were not affected; she could close both eyes, but not with such power the right as the left; both pupils seemed rather dilated. The pulse was slow and full. Respirations were natural. There was no cardiac hypertrophy, nor arcus senilis. She remained in this state for about a fortnight, when slight sensation returned into the extremities, the lower one first ; and power of speech, which had been completely in abeyance since the attack came on, returned to such an extent that she could now utter an inarticulate sound, which at last became developed into a Yes and a No. The urine, which for the first few days was rather cloudy, on applying heat and nitric acid, now showed no signs of albumen. She remained under treatment for six weeks ; but, as no appreciable improvement took place, it was deemed advisable to abstain from any treatment for the time being, at all events until after parturition, which was got over (I was made to understand) without any difficulty, the child being perfectly healthy.

When I again saw her, in a fortnight after the confinement, she was very weak, but gradually recovering her strength; able to move her leg and arm, but not to turn over in bed; sensation was almost perfect in both limbs; the buccinator was still flabby, it had not improved to the same extent as the extremities; she could utter a few easily pro: nounced monosyllables; was rather deaf. Her memory failed her, and her intellectual faculties generally were impaired. She would occasionally alternately laugh and cry, and did not seem easily to comprehend what was said to her. These symptoms made me fear that some permanent mischief was commencing.

At the end of the second month after parturition, she could walk about and use her arms, but both limbs felt rather weak; the buccinator was firm, but the ability to speak was still rather imperfect. The intellectual faculties had almost gained their natural state. The brain, which $I$ at one time feared had received a shock from which it would never recover, seemed to be gradually resuming its functions. The effusion which, I presumed, from the suddenness of the attack, the absence of any appreciable premonitory symptoms, the lividity of the countenance during the attack, and the other symptoms described, had taken place, seemed now gradually to become absorbed : and the patient seemed to be slowly but steadily improving, when I lost sight of her.

A Centenarian.-According to the Allgemeine Medicin. Central Zeitung, there is living in Bromberg a man, named Stanislaus Bagerewski, I 7 years old. 